\title{
A recente reforma dos serviços de saúde na província do Québec, Canadá: as fronteiras da preservação de um sistema público
}

\author{
Recent health services reform in Quebec \\ Province, Canada: on the frontier of preserving \\ a public system
}

Eleonor Minho Conill 1

1 Departamento de Saúde Pública, Núcleo de Apoio à Municipalização

e Implementação do SUS em Santa Catarina,

Universidade Federal de

Santa Catarina. Campus Universitário Trindade,

C.P. 476, Florianópolis, SC 88040-970, Brasil.

eleonor@repensul.ufsc.br

\begin{abstract}
This paper analyzes recent changes in the Canadian health system through a case study of Quebec. As the last Province to adopt federal principles of universal coverage, comprehensiveness, and public management, its reform, conducted in 1971, met these objectives by means of key innovations. In the 1980s and early 90 s, a process of health services evaluation in this Province and in Canada as a whole launched a period of extensive changes. The relevant measures are described herein: decentralization and regional management, "clinical shift", selective reduction in the supply of services, and new mechanisms for resource allocation and social control. There is a tendency towards an environment of public competition, but the approach that was adopted for regulation does not correspond to the main models from central countries. Within a scenario of budget constraints, technocratically-defined measures allowed for the settlement of benefits, preserving the system's main guidelines. This evidence is one of the main contributions of comparative analysis to health system reform in peripheral countries. The study identifies the relationships between these measures and a worldwide trend towards cost control and macroeconomic adjustment policies, discussing the relevant implications for health services.
\end{abstract}

Key words Health Care Reform; Health Services; Public Sector

Resumo O trabalho analisa mudanças recentes no sistema de saúde canadense por meio do estudo de caso do Quebec. Última província a adotar princípios federais de universalização, integralidade e gestão pública, sua reforma realizada em 1971 ultrapassou esses objetivos com características inovadoras. Na década de 80 e início dos anos 90, ocorrem avaliações nessa província e no conjunto canadense, iniciando-se um período de transformações. As principais medidas em curso são descritas: descentralização e gestão regional, virada ambulatorial, redução seletiva da oferta, novos mecanismos de alocação de recursos e de controle social. Observa-se uma tendência para um ambiente de competição pública, mas o modo de regulação adotado não corresponde aos principais modelos discutidos para países centrais. Em um cenário de restrições orçamentárias, medidas tecnocraticamente definidas permitiram acomodar interesses, preservando princípios norteadores do sistema. Essa constatação é uma contribuição importante da análise comparada para reformas de países periféricos. Relações dessas medidas com a tendência de controle de custos e políticas de ajustes são apontadas, discutindo-se implicações nos serviços.

Palavras-chave Reforma Sanitária; Serviços de Saúde; Setor Público 


\section{Introdução}

Na década de 70, a organização dos serviços de saúde da província do Québec, Canadá, se destacava pelo caráter inovador das ações empreendidas. Num país de 29,5 milhões de habitantes que fala predominantemente inglês, o Québec, a mais extensa das dez províncias canadenses, tem uma população de 7,1 milhões, majoritariamente francófona (Gouvernement du Québec, 1995). Nessa década, essa especificidade cultural constituía-se num dado fundamental para a compreensão não apenas de suas características sócio-econômicas, mas também do estilo de intervenções do Estado nas políticas públicas, incluindo a reforma dos serviços sociais e de saúde realizada em 1971.

Última província a implantar o seguro saúde universal na década de 60 (The Medical Care Act, 1966), o Québec ultrapassou em muito os princípios estabelecidos pelo governo federal, realizando uma verdadeira "revolução tranqüila” no setor saúde (Renaud, 1976). Tais princípios eram: a universalização, a integralidade e a gestão pública dos sistemas provinciais, com base em orçamento fiscal e financiamento compartilhado entre os dois níveis de governo. A descentralização é outra característica importante, tendo as províncias grande liberdade na organização do modelo assistencial e nas relações com os prestadores, desde que respeitado esse quadro legal.

A expressão "revolução tranqüila" foi amplamente utilizada para caracterizar as importantes transformações econômicas e sociais que ocorreram no Québec, a partir de meados de 1950, quando essa província passa rapidamente de uma sociedade rural, católica, dominada por elites tradicionais, para uma sociedade moderna, capitalista avançada. Em termos de políticas sociais, significou a emergência de um discurso que associava elementos ao mesmo tempo racionalizadores e democráticos na organização dos serviços.

A reforma do Québec foi considerada um exemplo de aplicação de uma política de saúde comunitária pelo fato de enfatizar-se, entre outros aspectos, a comunidade, geograficamente definida, como ponto central da organização do modelo assistencial. Na porta de entrada do sistema, composto de uma rede hierarquizada de estabelecimentos (13 regiões), foram criados os Centros Locais de Serviços Comunitários (CLSC), cujo conselho de administração era, e é até hoje, majoritariamente constituído por usuários.

O contexto e a evolução de dez anos da reforma (1970-1980) foram objetos de análise.
Essas organizações, embora fornecendo um cuidado mais integral, transformam-se gradativamente em estruturas marginais, dirigidas para o cuidado em domicílio de idosos, complementares aos consultórios médicos, mantidos por meio do credenciamento universal. De duzentos CLSC previstos, apenas cem estavam implantados no início da década de 80, após uma fase de avaliação e contenção. Os consultórios dos hospitais (35\%) e os médicos em prática privada, em geral em policlínicas (44\%), respondiam por aproximadamente $80 \%$ dos cuidados de primeira linha. Esses serviços, com procura crescente da emergência, constituíam a verdadeira porta de entrada. Os médicos praticando nos CLSC representavam, na época, um pouco menos de $10 \%$ dos generalistas da província (Conill, 1982).

Embora essa situação dos efetivos médicos tenha se modificado pouco, e os CLSC totalizem hoje um número de 151 estabelecimentos, eles voltam surpreendentemente à cena no final da década de 90 , em virtude da chamada virada ambulatorial (L. Rocheleau, comunicação pessoal). Essa proposta, associada à redução de leitos hospitalares, constitui a pedra angular das ações desencadeadas após a nova lei (Lei 120) sobre os serviços sociais e de saúde (Assemblée Nationale, 1990).

Como veremos a seguir, essa estratégia, talvez a mais importante no momento, visa uma contenção dos gastos mediante a diminuição de internações, pela realização de cirurgias de um dia e de cuidados contínuos assegurados a pessoas idosas ou deficientes em ambiente domiciliar (Angus et al., 1995; MSSS, 1997). Para alguns, isso significa que, se os CLSC não conseguiram ser a porta de entrada do sistema, podem vir a ser a de saída (Dieudonné, 1997). Para outros, esse novo período pode ser útil, propiciando uma desinstitucionalização necessária e uma revisão do modelo assistencial. Permitiria uma melhor complementaridade entre as estruturas e uma ênfase na prevenção e promoção da saúde (Contandriopoulos, 1996; MSSS, 1997).

Quais as transformações em curso e quais as tendências em jogo? Em que contexto específico se situa a atual reforma e quais suas possíveis implicações no acesso e na qualidade dos serviços? Essas são algumas das questões tratadas neste texto. Seu conteúdo provém de entrevistas com dirigentes do Ministério da Saúde e de Regionais de Saúde, Federação dos Médicos Generalistas e dos Centros Locais de Serviços Comunitários, professores e/ou pesquisadores participantes de comissões ou pesquisas relacionadas com o tema, complementadas por pesquisa de documentos, realizada nas cidades de Montreal e Québec, em 1997. 
A primeira parte contextualiza a reforma, discutindo as re lações entre globalização, déficit público e propostas de regulação, visando controlar custos setoriais. Mostramos que, tal como já tem sido apontado, o que ocorre no Québec e no Canadá corresponde a uma tendência mundial (Contandriopoulos et al., 1993; Almeida, 1995). Em seguida, descrevemos a evolução e a situação atual das propostas, discutindo, em conclusão, alguns aspectos de sua problemática.

Argumentamos que, embora algumas das medidas implementadas impliquem ameaças às conquistas obtidas, o apoio social ao princípio de solidariedade que constitui sua base, assim como a manutenção de suas linhas norteadoras iniciais, torna importante o acompanhamento desse processo de reforma. Acompanhálo significa observar a fronteira possível entre as pressões dos ajustes macroestruturais no setor e a aparente intenção política de continuar garantindo um sistema universal de administração pública, voltado para resultados em saúde, relativamente bem-sucedido.

\section{Globalização de medidas de contenção em saúde, déficit público e as reformas no Québec e no Canadá}

Embora um conjunto de avaliações e recomendações sobre o sistema de saúde tenha se acumulado ao longo da década de 80 e início dos anos 90 (MSSS, 1988, 1989, 1990, 1993), as transformações foram desencadeadas pela necessidade de realizar cortes no orçamento da saúde para fins de controle do déficit público e alcance da meta governamental de déficit zero até o ano 2000. Os gastos com saúde correspondem a $31 \%$ do orçamento da província, seguidos por educação (26\%) e reembolso de dívida (14\%). Uma série histórica da variação dos recursos para saúde mostra uma redução paulatina, chegando-se a valores negativos a partir de 1995 . Entre 1996 e 1997, com essa diminuição e o congelamento de despesas, a variação negativa foi da ordem 5,8\% (MSSS, 1996).

Os argumentos para essa medida baseiamse na análise do nível e da composição das despesas. Em 1993, comparando-se com os países da OCDE (Organisation de Coopération et de Développement Économique), o Québec ocupava o segundo lugar em termos de gastos, medidos em porcentagem do PIB $(10,1 \%)$, sendo a primeira entre as províncias canadenses. A parte privada das despesas tem aumentado em todo o país nos últimos vinte anos. Embora, em 1994, representassem, no Québec, 27\%, o que corresponde à média canadense, o aumento teria ocorrido mais rapidamente nessa província.

A análise das despesas per capita traz um enfoque diferente para a questão, pois o Québec situa-se em posição inferior a outras províncias e, inclusive, à média canadense, com valores de CAN\$2.174,00 versus CAN\$2.360,00 (Lamarche \& Rossi, 1995).

Champagne et al. (1992) mostraram, também, que os gastos mantiveram-se relativamente estáveis desde a introdução do seguro universal, não havendo evidências de sua contribuição para o aumento da dívida. Comparando-se evolução do $\mathrm{PNB}$, gastos com saúde e dívida pública no Canadá e no Québec, de 1975 a 1991, nota-se que os gastos em saúde acompanharam a tendência do PNB, apresentando um discreto crescimento. Já a dívida pública teve um crescimento muito maior.

Para o documento ministerial, três aspectos seriam preocupantes: despesas hospitalares (mais altas do país), crescimento acelerado do número de médicos de 1981 a 1992 e decréscimo constante dos recursos federais $(25 \% \mathrm{em}$ dez anos).

Ainda que com características relativamente distintas em seus diagnósticos, a preocupação com controle de custos não se constitui num privilégio do Québec. Torna-se discurso corrente no enfrentamento da crise das finanças públicas, justificado pelo receituário neoliberal de equilíbrio macroeconômico, menos interferência do Estado e maior flexibilização das regulamentações e das relações de trabalho, para retomada do crescimento econômico e criação de empregos no contexto competitivo da globalização.

Lamarche \& Rossi (1995) mostram esse movimento no cenário canadense comparando resultados de cinco comissões criadas entre os anos 80 e 90, para avaliar a situação do sistema de saúde nas províncias de Nova Escócia, Québec, Ontário, Saskatchewan e Colúmbia Britânica. Pela Constituição canadense, a organização dos serviços é de competência provincial, não existindo um sistema de saúde canadense, mas, sim, dez sistemas provinciais (e dois territoriais). Para receber os subsídios federais, esses sistemas devem respeitar os princípios citados na introdução deste trabalho, reiterados em lei canadense de 1984 sobre a saúde. O respeito a esses princípios faz com que haja mais semelhanças que diferenças, no entanto, como a contribuição federal para a saúde tem diminuído, caindo de $50 \%$ em 1978 para $22,7 \%$ em 1994 (Santé Canadá, 1994, apud Lamarche \& Rossi, 1995), o poder de regulação federal também tende a diminuir. 
A comparação da problemática nas províncias mostra convergência em torno dos seguintes problemas: custos, dificuldades de adaptação dos serviços a necessidades, dinâmica inflacionista e baixa efetividade, ou seja, ausência de uma boa relação entre despesas e indicadores de saúde. As soluções propostas variaram de uma província para outra, mas giram em torno de eixos comuns. Primeiramente, a já conhecida e retórica prioridade em objetivos de saúde e serviços de primeira linha, prevenção e promoção. Para as estruturas de decisão, é sugerido separar saúde e serviços (diferenciação). Na gestão de recursos humanos, controle da demografia médica e diminuição do pagamento por ato. Há, como novidade, a proposta de aumentar a utilização de outros profissionais que possam constituir-se em alternativas eficazes aos serviços médicos. Na gestão dos recursos financeiros, nenhuma das comissões recomenda aumentá-los, pelo contrário; não questionam o financiamento público, porém sugerem revisão das relações com o governo federal e o reconhecimento da contribuição potencial, mas limitada, de um financiamento privado.

Um estudo quantitativo avaliou os modos de regulação dos sistemas de saúde das províncias canadenses e de alguns países industrializados, visando determinar quais dispositivos de regulação de custos eram mais efetivos (Contandriopoulos et al., 1993). Os países e as províncias foram posicionados num ranking em virtude do desempenho dos sistemas em controlar custos e em produzir resultados em saúde (rendimento), medidos pela esperança de vida e mortalidade infantil, no período 1980-1987.

O presente trabalho introduz uma dimensão importante na análise da contenção de custos, que é a sua relação com resultados. Visto desse ângulo, os países da OCDE mostram uma melhor performance que o Canadá; o Québec, contrariamente ao enfocado no documento ministerial (1996), situa-se na média das províncias. Os resultados das medidas reforçam aspectos já conhecidos: quanto mais centralizada a gestão e menor o número de fontes de financiamento, maior o rendimento e a capacidade de controlar custos; quanto maior a presença do setor privado menor controle e rendimento; formas de remuneração médica por salário, capitação ou por meio de terceiros são menos onerosas que o pagamento por ato ou diretamente pelo paciente.

O melhor controle de gastos hospitalares das províncias canadenses, entre as quais inclui-se o Québec, foi decorrência basicamente da diminuição do número de dias de hospitali- zação, número de leitos por habitantes e dos custos unitários de hospitalização. Uma das melhores capacidades de controle de custos dos serviços médicos foi observada no Québec, associada a um baixo crescimento de honorários Os autores concluem que há convergência das estratégias utilizadas, que seriam essencialmente: descentralização, financiamento via orçamento global determinado por critérios sanitários e populacionais, desenvolvimento de alternativas à hospitalização, aumento do financiamento via contribuição dos usuários e controle da demografia médica.

Essas estratégias coincidem, em parte, com aquelas identificadas por Almeida (1995), num extenso trabalho sobre as reformas dos anos 80 em cinco países centrais (Estados Unidos, Reino Unido, Suécia, Alemanha Ocidental, Itália e Espanha). Além das medidas de contenção de custos, a competição seria a tônica dessas reformas representada pela competição administrada proposta para os Estados Unidos, pelo mercado interno da reforma inglesa (1989/ 1991) e pela competição pública desenvolvida na Suécia.

A reforma em curso no Québec parece inspirar-se em alguns elementos do modelo de competição pública. Embora, no âmbito tanto canadense, como provincial, os grandes princípios tenham sido preservados, a diminuição das fontes de financiamento determina, sem dúvida, uma tensão. Vejamos, adiante, quais os mecanismos implementados, formulando em seguida algumas hipóteses sobre suas conseqüências.

\section{Das propostas à prática: descrição das transformações em curso no sistema de saúde do Québec nos anos 90}

A trajetória do sistema de saúde quebequense pode ser dividida em três etapas. Na primeira década, de 1970 a 1980, o sistema é implementado, estabelecendo-se seus fundamentos e garantindo-se o acesso. Na segunda, de 1980 a 1990, à medida que é consolidado, desenvolvem-se reflexões e avaliações sobre seu funcionamento. A terceira, mais visível a partir de 1995, caracteriza-se pela implementação das atuais transformações (MSSS, 1997).

O marco formal da etapa de reflexão é a constituição pelo governo provincial, em 1985 (Decreto-Lei 1.156), de uma Comissão de Inquérito sobre a saúde e serviços sociais, denominada Comission Rochon, em razão do nome do seu presidente. Essa Comissão trabalhou durante dois anos, realizando encontros, con- 
sultando praticamente todos os organismos representativos do setor, encomendando um conjunto de pesquisas como subsídios, concluindo suas atividades em dezembro de 1987 (MSSS, 1988).

Para a comissão, o sistema tinha se tornado prisioneiro dos diversos grupos de interesse, faltando-lhe objetivos epidemiológicos. Sugere, então, uma nova dinâmica de poderes: em nível decisório (conselhos de administração, participação dos usuários), em nível dos serviços (programas, ênfase na continuidade e avaliação) e em nível dos recursos humanos (distribuição, formação, negociação). Acorda importância aos sistemas de informação e à alocação de recursos, condicionando-a aos planos plurianuais.

Nos anos posteriores, seguindo muitas dessas recomendações, o governo publica quatro documentos básicos, que marcam o quadro normativo, institucional e legal da nova reforma.

O primeiro deles, de abril de 1989, traça as novas diretrizes, sendo conhecido como Orientations (MSSS, 1989). Reforçando a intenção de manter um sistema público forte, o documento inicia fixando objetivos de forma interessante: somar anos à vida (percentuais de reduções de mortalidade por doenças cardiovasculares, câncer de mama, acidentes etc.); somar saúde à vida (percentuais de redução de dor lombar, de doenças sexualmente transmissíveis, de fumantes, entre outros) e somar bem-estar à vida (autonomia, saúde mental, redução da violência, por exemplo). Há ênfase na descentralização, atribuindo-se um novo papel às regionais e estabelecendo outro modelo de participação e controle social.

Os dois documentos que se seguem - Une Réforme Axée sur le Citoyen (MSSS, 1990) e a nova lei sobre os serviços de saúde e os serviços sociais, Loi 120 (Assemblée Nationale, 1990) estabelecem definitivamente as bases da nova reforma. O título e a organização do documento expressam o apelo à figura do cidadão como suporte às novas medidas. As estratégias são classificadas em três grupos: para o cidadão que é consumidor, para o cidadão que deve decidir e para o cidadão que é financiador.

Finalmente, o documento Santé et Bien-Être, la Perspective Québecoise, definindo a política social e de saúde, publicado em 1993, completa o conjunto. Reitera os objetivos explicitados no Orientations, reafirmando a garantia dos direitos através de serviços mais acessíveis, contínuos e complementares num sistema fortemente descentralizado. Adaptação social, saúde física, saúde pública, saúde mental e integração social compõem os grupos de objetivos que deverão transformar-se em programas. Uma alocação de recursos adequada às necessidades, a avaliação de resultados e da eficiência dos serviços são considerados grandes desafios. O novo organograma do sistema mostra busca de flexibilidade e diversidade nos prestadores, pois, além dos serviços públicos, aparecem consultórios, outros serviços privados e comunitários.

Embora extremamente coerentes entre si, criando um sólido referencial, poucas mudanças expressivas ocorrem até a metade dos anos 90. As diferenças passam a existir principalmente a partir de 1994, quando Jean Rochon, presidente da Comissão de Inquérito na década anterior, é nomeado Ministro da Saúde, e o cerco de cortes orçamentários em direção ao Déficit Zero é deflagrado. De 1995 a 1997, o ritmo das transformações intensifica-se.

\section{A descentralização e o novo papel \\ da gestão regional: a difícil tarefa \\ de administrar cortes orçamentários}

Na reforma dos anos 70, o Québec foi dividido em 13 regiões sócio-sanitárias, criando-se em cada uma um Conseil Régional de la Santé et de Services Sociaux (CRSSS), com funções genéricas e de tipo essencialmente consultivo (integração da rede e recebimento de queixas, por exemplo) (Conill, 1982). Os estabelecimentos relacionavam-se diretamente com o Ministério da Saúde da província.

Ao longo da década de 80, a descentralização apontada nas diferentes propostas preconiza um novo papel para a gestão regional (MSSS, 1989). O número de regiões aumenta para 17 , sendo os Conselhos transformados em Régies de la Santé et des Services Sociaux, com personalidade jurídica e autonomia funcional. Suas atribuições incluem: promover a participação e proteger direitos dos usuários, programação, alocação de recursos, coordenação e "tables de concertation" de interesses (estabelecimentos, profissionais, organismos comunitários), controle e avaliação. Podem, por exemplo, sem licença do Ministério, autorizar trabalhos inferiores a um milhão de dólares em hospitais e, em outros estabelecimentos, aqueles inferiores a 250 mil dólares canadenses, devendo todo e qualquer plano de expansão contar com seu parecer.

A Lei 120 de 1990 dá o suporte legal a essas propostas, e esse novo agente de descentralização constitui-se numa das principais novidades. Essas agências regionais incorporam também ações de saúde pública, por meio da integração dos Departamentos de Saúde Comunitária, antes sediados em hospitais. 
Apesar do enquadramento legal, suas atividades iniciam paulatinamente, intensificandose, a partir de 1994, com a elaboração dos chamados Planos de Organização e de Transformação da Rede. Coube-lhes administrar a alocação de recursos reduzidos, promovendo cortes de pessoal, incentivando aposentadorias precoces e fusões de estabelecimentos. Isso é realizado de diferentes formas, mas um dos mecanismos utilizados são as chamadas reuniões de consenso, também denominados "tables de concertation".

O desafio é modificar o sentido das restrições orçamentárias, apresentando-as como transformações necessárias para adequar as práticas às necessidades regionais. Tal adequação tem como eixo estudos de prioridades realizados nos anos anteriores, que devem ser compatíveis com os 19 objetivos enumerados na Política de Saúde e Bem-Estar (MSSS, 1993). Tarefa que os entrevistados foram unânimes em classificar como difícil pela velocidade com que as mudanças estão sendo realizadas, pela tendência setorial de gastos crescentes e recursos limitados.

Objetivos de saúde e bem-estar, descentralização e democratização compõem o discurso da reforma tendo nas Agências Regionais um de seus principais protagonistas institucionais. O Ministério pretende ainda ampliar o leque dos desafios, acrescentando propósitos de busca de eqüidade na alocação de recursos entre as regiões e estímulo à competição entre os estabelecimentos. As regionais terão autonomia para investir naqueles que se propuserem a realizar mais e/ou melhor, com menos recursos.

Atualmente, a alocação é feita com bases populacionais. Há, no entanto, um histórico de direitos adquiridos com distorções de oferta, que fazem com que certas regiões recebam mais, como é o caso de Montreal. A fórmula a ser implantada num futuro próximo deverá incorporar indicadores de necessidades, tais como: idade, sexo, esperança de vida e escolaridade (M. Alberton, comunicação pessoal).

\section{A redução seletiva da oferta e o virage ambulatoire}

Fusão de estabelecimentos, fechamento de hospitais e a chamada virada ambulatorial são outros acontecimentos de impacto da atual reforma. Resultam dos já mencionados planos de transformação da rede, objeto da ação das Agências Regionais.

Em abril de 1995, início das transformações, havia 477 Conselhos de Administração para gerenciar 629 estabelecimentos; em janei- ro de 1997, tem-se 396 para 459 estabelecimentos (MSSS, 1997). O princípio é a fusão ou a integração de Conselhos de organismos de mesma natureza ou complementares. Assim, ocorreram fusões, por exemplo, entre CLSCs, com pequenos hospitais e casas de repouso.

Surpreendente, no entanto, é a virada ambulatorial, expressão não relevante nos documentos que dão base à reforma, mas que surge como uma das temáticas mais enfatizadas na atualidade. Para o Ministério (MSSS, 1997), é um dos eixos da transformação implantando medidas para diminuir a procura por recursos institucionais (principalmente a utilização de leitos para doenças agudas) e tornando disponíveis serviços que responderiam melhor as necessidades da população. O objetivo de quatro leitos de agudos por mil habitantes foi substituído pela meta de dois, e essa é a principal estratégia para obtê-lo.

O tema da cirurgia ambulatorial, carro chefe da virada, é tratado em uma série de artigos (Colloudon, 1997; Laurion, 1997; Provencher, 1997) na revista oficial da Federação dos Médicos Generalistas do Québec (FMOQ). O editorial que precede os artigos resume seu aval afirmando: “Após muitas dores de cabeça, descobrimos com os pacientes as múltiplas vantagens dessa proposta" (Provencher, 1997:25).

Atualmente, $60 \%$ das cirurgias estariam sendo realizadas com tempo de permanência inferior a 24 horas, com uma satisfação em torno de $90 \%$ e demanda crescente (Coulloudon, 1997; Laurion, 1997). Laurion (1997) mostra, contudo, que, para representar economia, não pode haver aumento importante de cirurgias, como ocorreu com a colecistectomia após o uso do laparoscópio (mais de 50\%). Apesar do cálculo de uma economia da ordem de 400 dólares por caso de cirurgia ambulatorial (MSSS, 1995 apud Laurion, 1997), esse impacto será provavelmente diferente tratando-se de um pequeno ou de um grande hospital. No primeiro, poderá haver diminuição de leitos, mas, no segundo, com demanda reprimida, haverá uma seleção para internação dos casos mais graves, portanto, de alto custo. Como o primeiro tipo de hospital é predominante, espera-se que haja melhoria do acesso e contenção de custos.

Além do aumento das cirurgias ambulatoriais e diminuição de leitos, o MSSS (1997) enumera outros resultados positivos dessa estratégia: aumento da disponibilidade nos CLSC (60 horas/semana), informações por telefone 24 horas (Info-Santé/CLSC), seguro para medicamentos, diminuição da permanência nos serviços de urgência, diminuição do tempo para coleta de exames, organização de rede integra- 
da de hospitais universitários e diminuição pela metade do número de circulares administrativas. Afirma estar garantindo a contrapartida financeira dessas mudanças, por exemplo, com um aumento de 20,6\% nos anos de 1996-1997 para os serviços em domicílio. Apóia-se, também, num estudo de satisfação feito pela Regional de Québec, em 1996, no qual 95\% dos usuários se mostravam satisfeitos com os serviços em consultório; $90 \%$, em CLSC, e 83\%, em hospitais, locais aos quais voltariam, na mesma situação, em 96\%, 87\% e 88\% dos casos (MSSS, 1997).

Quanto à alocação de recursos, será necessário acompanhar se os aumentos divulgados para a primeira linha são sustentados e compatíveis com as necessidades determinadas pelo seu novo e destacado papel. Essa avaliação e estudos de qualidade permanecem ainda com uma interrogação.

\section{Um novo modelo de participação}

Numa perspectiva internacional comparada, um dos aspectos particulares das atuais medidas é a manutenção do discurso participativo e a ênfase nele, ao passo que, na maior parte das demais reformas dos países centrais, tal discurso é substituído pelo da gerência e eficiência.

Com um modelo anterior que previa a participação majoritária de usuários nos Conselhos de Administração dos CLSC, o Québec apresentou-se como um dos locais em que as propostas de democratização foram expressivas, possibilitando muitos estudos, entre os quais destacam-se os de Godbout (1979a, 1979b, 1981, 1983, 1986). Apesar de seus trabalhos indicarem uma tendência de a participação dos usuários tornar-se instrumental e mostrarem suporte à tecno-burocracia ou a grupos militantes, a importância da incorporação desse novo ator para a inovação institucional é reconhecida (Godbout, 1979a, 1979b, 1981; Conill, 1982; O’Neill, 1992).

Por considerar que a influência dos usuários foi realmente limitada, já o primeiro documento da nova reforma (MSSS, 1989) mostra disposição de ampliá-la. O que caracteriza o novo modelo é a ênfase na participação em nível regional. Nota-se a intenção de diversificar os atores e de garantir uma intersetorialidade com incorporação de representantes do setor privado, organizações comunitárias, meio escolar e municipalidades. Introduz-se um mecanismo denominado cooptação, através do qual o conselho de administração dos estabelecimentos pode ser completado com pessoas escolhidas pelos membros eleitos, a fim de garantir conhecimento técnico ou representativida- de. A tendência mais recente é a eliminação de representantes dos funcionários em favor de cooptados, já que, no modelo anterior, o conselho de administração transformou-se, algumas vezes, numa arena de disputa entre o diretor geral e os funcionários em torno de questões sindicais ou corporativas. A busca atual do Ministério parece dirigir-se para fóruns que legitimem, em última instância, sem muito conflito, suas ações, permitindo uma adequação local das medidas de contenção.

Esse estilo de regulação pode caracterizarse como sendo de tipo tecnocrático, segundo Champagne et al. (1992), os quais fazem uma análise interessante das opções políticas e administrativas que caracterizaram a reforma quebequense, cujos elementos são úteis para a reflexão final sobre suas tendências.

\section{Preservação do possível, uma nova dinâmica nos serviços ou privatização tranquila? Considerações finais sobre possíveis tendências do sistema de saúde no Québec}

A rigor, as medidas implementadas na atual reforma não correspondem a nenhum dos principais modelos de regulação discutidos para sistemas públicos dos países desenvolvidos, a partir da década de 80: competição pública, mercado interno ou incentivos gerenciais.

Esses modelos surgem de combinações entre os três principais pólos de poder que influenciam a configuração do sistema de saúde: o pólo tecnocrático, o profissional e o dos usuários. No caso do Québec, teria havido uma mistura de elementos desses pólos, com predominância do primeiro (Champagne et al., 1992).

Na tentativa de estabelecer uma nova dinâmica, apostou-se na descentralização, na participação e na gerência centrada em resultados, decorrente de um forte enquadramento tecnocrático e restrições orçamentárias. A reforma ofereceu, sem dúvida, um sólido e renovado referencial para a política de saúde, mas seus resultados concretos na reorganização das práticas assistenciais merecem algumas ponderações.

Embora não seja possível caracterizá-lo como o modelo de regulação escolhido, nota-se uma tendência a imprimir um ambiente de competição pública entre as instituições. Para Almeida (1995), esse modelo recobriria um conjunto amplo de atividades cuja configuração pode variar em cada contexto, mas a essência é a manutenção da estrutura pública de alocação de recursos. A competição pública relaciona a remuneração dos prestadores à sua capa- 
cidade de atrair pacientes e ao cumprimento de alguns indicadores. É uma proposta voltada para sistemas públicos visando estimular o uso mais eficiente e efetivo de recursos, reforçando estruturas descentralizadas, priorizando atenção primária localmente controlada, com ênfase na promoção e prevenção. A satisfação e a escolha dos pacientes seriam objetivos principais desse modelo, juntamente com acesso universal e eqüidade, o que, segundo a autora, significaria retirar do conceito de escolha individual sua relação com o valor de troca.

A competição pública baseia-se na preferência do usuário como garantia da eficiência. O orçamento de fontes fiscais é dividido pelas instituições conforme sua capacidade de atraílos, o que exige flexibilidade na alocação e condições de trabalho. Desse ponto de vista, essa não é a dinâmica preponderante na atual reforma, marcada por transformações e ajustes normativos tecnocraticamente determinados, num quadro orçamentário recessivo.

Outro aspecto de importância é a forte influência da corporação médica na preservação de sua autonomia. Mesmo com controle governamental sobre suas rendas, essa influência garantiu a manutenção do mecanismo de pagamento por ato, regulado de forma centralizada, em nível provincial. Isso engendra uma contradição para administradores das regionais e instituições, pressionados a conter custos determinados, em grande parte, pela centralidade da prática médica no sistema. As medidas gerenciais e organizacionais impactam de forma apenas indireta nessa prática, como é o caso, por exemplo, da cirurgia ambulatorial.

As políticas públicas resultam de um complexo processo, baseado na interação entre percepção/expressão dos problemas, soluções disponíveis e condições políticas. Nesse sentido, é possível pensar que a reforma representa uma acomodação possível de interesses, tentando preservar grandes princípios.

O que permanece relativamente intocável é a discussão sobre as relações entre aumento de gastos com saúde, controle do déficit público e restrições às políticas setoriais. Champagne et al. (1992) questionaram essa relação mostrando que o crescimento da dívida pública foi muito superior ao do PNB e ao dos gastos com saúde no Canadá e no Québec, de 1978 a 1991. Giovanella (1998) discute os mitos, a retórica e os consensos em torno da questão com base nas reformas do sistema de saúde alemão e mostra que há, também, um problema de erosão de receitas determinado pelo desemprego nos países centrais, aspecto cuja importância é geralmente negligenciada em favor de uma explica- ção concentrada nas pressões tecnológicas e no envelhecimento da população.

A idéia da importância da atenção primária e dos cuidados de primeira linha é antiga no âmbito das reformas dos sistemas de atenção médica e faz parte do ideário da primeira reforma (Gouvernement du Québec, 1970). A novidade é a sua ênfase num contexto recessivo, o que associado à criação de um seguro público para assistência farmacêutica, diminuição de leitos de agudos e cuidados em domicílio pode significar, acima de tudo, desinstitucionalização de formas custosas de atenção.

A rapidez com que as medidas estão sendo implementadas, em face das restrições orçamentárias impostas, é motivo de preocupação para muitos dos entrevistados. O temor é de que a rapidez com que os cortes se realizam possa levar a uma perda da qualidade dos serviços, desencadeando um processo sutil de privatização, uma privatisation en douceur. Se é no jogo político que reside a esperança de um balizamento favorável aos usuários, cabe a indagação sobre suas reais possibilidades no atual cenário quebequense, onde as regras parecem ser muito mais impostas do que negociadas. É possível que se abram mercados em áreas específicas complementares ao sistema de cuidados público, como, por exemplo, cuidados domiciliares ou exames complementares. Mas, não há um recuo importante nos grandes princípios do sistema.

Estudos dessa ordem trazem subsídios para a análise das propostas de reforma para países periféricos. É importante chamar a atenção não apenas para aquilo que essas reformas mudaram mas também para o que preservaram, como cobertura universal, base solidária do financiamento, responsabilidade pública pela provisão (direta ou não) dos serviços e o controle estatal sobre o funcionamento do sistema (Saltman, 1994, apud Almeida, 1995). Saltman, ao discutir o impacto das reformas européias na eqüidade, destaca que foram melhor sucedidas aquelas que apostaram em mecanismos inovadores de reorganização da oferta, do aquelas que realizaram privatização da demanda (Saltman, 1997).

Pôr em relevância esses aspectos é uma contribuição importante da análise comparada para os tortuosos reordenamentos dos sistemas de saúde de países periféricos, tendo em vista as constantes pressões contrárias às escassas conquistas obtidas. Num cenário recessivo convergente para políticas sociais, é útil conhecer os diversos mecanismos que garantem diferenças entre os sistemas de saúde, permitindo a preservação de sistemas de proteção universal e financiamento solidário. 


\section{Agradecimentos}

A autora agradece ao governo canadense, que, através do programa Bourses de Complément de Spécialisation en Études Canadiennes, tornou possível a realização desta pesquisa.

\section{Referências}

ALMEIDA, C. M., 1995. As Reformas Sanitárias dos Anos 80: Crise ou Transição? Tese de Doutorado, Rio de Janeiro: Escola Nacional de Saúde Pública, Fundação Oswaldo Cruz.

ANGUS, D. E.; AUER, L.; CLOUTIER, J. E. \& ALBERT, T., 1995. Pour un Système de Soins de Santé Viable au Canadá. Rapport de Synthése, Projets de Recherche Économique des Universités d'Ottawa et Queen's. Ottawa: Université d'Ottawa.

ASSEMBLÉE NATIONALE, 1990. Project de Loi 120, Loi sur les Services de Santé et les Services Sociaux et Modifiant Duverses Dispositions Législatives. Québec: Editeur Officiel du Québec.

CHAMPAGNE, F; CONTANDRIOPOULOS, A. P.; DENIS, J. C.; LEMAY, A. \& PINEAULT, R., 1992. Options for Health System Regulation: The Case of the Québec Health Care Reform. Groupe de Recherche Interdisciplinaire en Santé, Document no 9304. Montréal: Université de Montréal.

COLLOUDON, A., 1997. Le virage ambulatoire de la chirurgie. Le Médicen du Québec, 32:29-31.

CONILL, E. M., 1982. Les Implications de la Santé Communautaire en tant que Nouvelle Politique de Santé: Analyse du Cas du Québec. Thèse de Doctorat, Paris: Institut D'Étude du Développement Economique et Social, Université de Paris I/Sorbonne.

CONTANDRIOPOULOS, A. P.,1996. Entrevue. Revue Notre Dame, 6:14-27.

CONTANDRIOPOULOS, A. P.; CHAMPAGNE, F.; DENIS, J. L.; LEMAY, A.; DUCROT, S.; FOURNIER, M. A. \& DJONA, A., 1993. Description et Évaluation des Modes de Régulation des Systémes de Santé Canadiens et de Certains Pays Industrialiasés. Groupe de Recherche Interdisciplinaire en Santé, Document R 93-02. Montréal: Université de Montréal.

DIEUDONNÉ, J. B., 1997. CLSC et virage ambulatoire. Bulletin du Département de Médecine Sociale et Préventive de l'Université de Montréal, 16:17.

GIOVANELLA, L., 1998. Entre a Solidariedade e a Subsidiariedade, Políticas de Contenção no Seguro Social de Doença Alemão: "Terceira Etapa da Reforma da Saúde”. Tese de Doutorado, Rio de Janeiro: Escola Nacional de Saúde Pública, Fundação Oswaldo Cruz.

GODBOUT, J., 1979a. Les CLSC: Présentation générale. In: La Décentralisation en Pratique, Quelques Expériences Montréalaises, 1970-1977 (G. Divay \& J. Gobbout, eds.), pp. 123-168, Montréal: Institut National de Recherche Scientifique.

GODBOUT, J., 1979b. La distribution du pouvoir et les changements suscités par les CLSC. In: La Décentralisation en Pratique, Quelques Expériences Montréalaises, 1970-1977 (G. Divay \& J. Gobbout, eds.), pp. 169-238, Montréal: Institut National de Recherche Scientifique.

GODBOUT, J., 1981. Is consumer control possible in health care services? The Québec case. Interna- tional Journal of Health Services, 11:151-167.

GODBOUT, J., 1983. La Participation Contre la Démocratie. Montréal: Ed. Saint-Martin.

GODBOUT, J., 1986. La Démocratie des Usagers. Montréal: Boreal.

GOUVERNEMENT DU QUÉBEC, 1970. Rapport de la Commission d'Enquete sur la Santé et le Bien-Être Social. Québec: Editeur Officiel du Québec.

GOUVERNEMENT DU QUÉBEC, 1995. Le Québec Statistique. Québec: Publications du Québec.

LAMARCHE, P. A. \& ROSSI, C., 1995. Les systémes de services de santé em mulation. In: Médècine Préventive et Santé Publique au Canadá (P. S. Chandrakant, ed.), pp. 375-393, Québec: Les Presses de l'Université Laval.

LAURION, M., 1997. Virage ambulatoire: Économies ou gaspillage? Le Médecin du Québec, 32:75-79.

MSSS (Ministère de la Santé et des Services Sociaux), 1988. Rapport de la Comission D'Enquete sur les Services de Santé et les Services Sociaux. Québec: Gouvernement du Québec/Les Publications du Québec.

MSSS (Ministère de la Santé et des Services Sociaux), 1989. Pour Améliorer la Santé et le Bien-Être au Québec. Orientations. Québec: Gouvernement du Québec/Ministère de la Santé et des Services Sociaux.

MSSS (Ministère de la Santé et des Services Sociaux), 1990. Une Reforme Axée sur le Citoyen. Québec: Gouvernement du Québec/Ministère de la Santé et des Services Sociaux.

MSSS (Ministère de la Santé et des Services Sociaux), 1993. Direction Génèrale de la Planification et de l'Évaluation - Santé et Bien-Être la Perspective Québécoise. Québec: Gouvernement du Québec/ Ministère de la Santé et des Services Sociaux.

MSSS (Ministère de la Santé et des Services Sociaux), 1996. La Santé et les Services Sociaux. Enjeux et Orientations Stratégiques d'un Système en Transformation. Québec: Ministère de la Santé et des Services Sociaux/Gouvernement du Québec.

MSSS (Ministère de la Santé et des Services Sociaux), 1997. Portrait de la Transformation du Systéme de Santé et de Services Sociaux du Québec, à mi-chemin du Parcours (1995-1998). Québec: Service des Communications, Gouvernement du Québec.

O'NEILL, M., 1992. Community participation in Québec's health system: A strategy to curtail community empowerment. International Journal of Health Services, 22:287-301.

PROVENCHER, J., 1997. Virage ambulatoire chirurgical. Le Médecin du Québec, 32:25.

RENAUD, M., 1976. The Political Economy of the Québec State Intervention in Health: Reform or Revolution? Ph.D. Thesis, Madison: University of Wisconsin.

SALTMAN, R. B., 1997. Equity and distributive justice in European health care reform. International Journal of Health Services, 27:443-453. 